\title{
PERPETUAL FOREIGNER IN ONE'S OWN LAND: POTENTIAL IMPLICATIONS FOR IDENTITY AND PSYCHOLOGICAL ADJUSTMENT
}

\author{
QUE-LAM HUYNH, \\ San Diego State University \\ THIERRY DEVOS, and \\ San Diego State University \\ LAURA SMALARZ \\ lowa State University
}

\begin{abstract}
The perpetual foreigner stereotype posits that members of ethnic minorities will always be seen as the "other" in the White Anglo-Saxon dominant society of the United States (Devos \& Banaji, 2005), which may have negative implications for them. The goal of the present research was to determine whether awareness of this perpetual foreigner stereotype predicts identity and psychological adjustment. We conducted a series of studies with 231 Asian Americans and 211 Latino/as (Study 1), 89 African Americans (Study 2), and 56 Asian Americans and 165 Latino/as (Study 3). All participants completed measures of perceived discrimination, awareness of the perpetual foreigner stereotype, conflict between ethnic and national identities, sense of belonging to American culture, and demographics. In Study 3, participants also completed measures of psychological adjustment: depression, hope, and life satisfaction. All participants were students at a large, public university on the West Coast of the United States. Across studies, we found that even after controlling for perceived discrimination, awareness of the perpetual foreigner stereotype was a significant predictor of identity conflict and lower sense of belonging to American culture. From Study 3, we also found that, above and beyond perceived discrimination, awareness of the perpetual foreigner stereotype significantly predicted lower hope and life satisfaction for Asian Americans, and that it was a marginal predictor of greater depression for Latino/as. These results suggest that the perpetual foreigner stereotype may play a role in ethnic minority identity and adjustment.
\end{abstract}

\begin{abstract}
"Where are you from?" This benign question is commonly asked during social interactions, and the answer often leads to interesting conversations with strangers or acquaintances. But what if an answer like "Lincoln, Nebraska," "Baltimore, Maryland," or "Modesto, California" does not suffice for the questioner? Indeed, ethnic minorities, especially Asian Americans and Latino/as, are often asked follow-up questions like, "No, where are you really from?" or "I meant, where are you originally from?" (Liang, Li, \& Kim, 2004; Sue, Capodilupo et al., 2007). At least under some circumstances, experiences such as these may be perceived by some ethnic minorities as a message that they do not share the American identity or have in-group status; therefore, these experiences may have negative implications
\end{abstract}

(C) 2011 Guilford Publications, Inc.

Address correspondence to Que-Lam Huynh, Department of Psychology, San Diego State University, 5500 Campanile Drive, San Diego, CA 92182-4611; huynh.quelam@gmail.com.

Note. Items marked with an asterisk (*) are reverse-scored. 
for their identity and adjustment. Thus, in a series of three studies involving three major American ethnic minority groups, we sought to demonstrate that members of ethnic minorities are aware of this perpetual foreigner stereotype (Cheryan \& Monin, 2005; Devos $\&$ Banaji, 2005), and this awareness is linked to their sense of belonging to American society, sense of conflict between ethnic and national identities, and psychological adjustment.

\section{THE PERPETUAL FOREIGNER STEREOTYPE}

Although the United States is historically an immigrant nation with an ethnically and culturally diverse population, members of ethnic minority groups are often innocuously denied the American identity and treated as if they were perpetual foreigners." This especially is evident in recent research that shows an overwhelming propensity to more readily ascribe the American identity to European Americans rather than to ethnic minorities (Devos \& Banaji, 2005; Devos, Gavin, \& Quintana, 2010; Devos \& Heng, 2009; Devos \& Ma, 2008; Rydell, Hamilton, \& Devos, 2010). Even when ethnic minorities are explicitly judged to be American, implicitly, in the minds of both European Americans and some ethnic minorities (Asian Americans and Latino/as), being "American" is equated with being White.

The assumption that ethnic minorities do not fit the definition of what it means to be American may manifest itself in subtle, covert marginalizing incidents, such as questioning an individual's home-town, complimenting his/her command of the English language, or mistaking him/her as a foreigner (Liang et al., 2004). These behaviors comprise a contemporary form of racism called racial microaggression, whereby racism is disguised in supposedly benign behaviors and comments (e.g., Where are you from?) that convey strong messages of exclusion and inferiority (Sue, Capodilupo, et al., 2007). Even when the intent of perpetrators, who can be of any ethnic or racial group, is not malicious or racially motivated, it is in these seemingly harmless occurrences that ethnic minorities are told that they are somehow less American than European Americans.

Research on the extent to which ethnic minorities are aware of being stereotyped as foreigners is limited. In a study on identity denial, or the acceptance threat that results when an individual who does not match the prototype of an in-group sees his/her identity called into question or unrecognized by fellow group members, Asian Americans were indeed aware of being denied the American identity by others despite the fact that they feel just as American as European Americans (Cheryan \& Monin, 2005). The study also identified situations of identity denial in everyday interactions for Asian Americans and Latino/as, who reported being misperceived as being from another country or a nonnative English speaker significantly more often than European Americans. Similarly, African American and Cuban American women reported feeling excluded from the national category by European Americans (Barlow, Taylor, \& Lambert, 2000). Although these experiences may be qualitatively different for Asian Americans and Latino/as (who are likely to be mistaken as immigrants when they are native-born) than for African Americans (who are likely to experience other forms exclusion from the American identity as a result of the "exclusionary patriotism" discussed below; Sidanius \& Petrocik, 2001), these findings suggest that overall, ethnic minorities are aware that they are perceived as less American and, in some cases, more foreign than European Americans.

\section{PERPETUAL FOREIGNER STEREOTYPE AND IDENTITY}

Although the denial of ethnic minorities' American identity is a phenomenon that has been identified in the literature (e.g., Cheryan \& Monin, 2005; Devos \& Banaji, 2005; Sue, Capodilupo, et al., 2007), the link, if any, between awareness of this perpetual foreigner 
stereotype, identity, and psychological adjustment has not been directly examined. In terms of identity, Cheryan and Monin (2005) found that identity denial impacted Asian Americans' everyday behavior, especially when they felt that their American identity was in question. In response to identity threat, they used identity assertion techniques, such as demonstrating awareness of popular American culture and engaging more in American practices to assert their American identity. In Barlow et al.'s (2000) study with African American women, feelings of exclusion from the national identity by European Americans were related to how African American women perceive their own group, such that those who felt more excluded held more pessimistic views of the economic and social position of African Americans, regardless of their actual socioeconomic status. Researchers have also identified a significant and negative correlation between perceived prejudice and negative self-concept among Japanese Americans, suggesting that the more this minority group was aware of negative prejudice against them, the more negatively they viewed themselves (Asamen \& Berry, 1987). These findings all indicate a potential link between how an individual believes he/she is perceived by others and his/her own perception of the self. In the present research, we were particularly interested in the association between awareness of the perpetual foreigner stereotype and subjective reports of conflict between one's ethnic and national identities, as well as feelings of belonging to mainstream American culture.

Conflict Between Ethnic and National Identities-If minority groups are, to some extent, cognizant that they are psychologically denied the American identity, we expect that the awareness of being perceived as a foreigner may account for subjective reports of internal conflict between their ethnic and national identities. Benet-Martínez and Haritatos's (2005) work on bicultural identity integration indicated that some bicultural individuals have difficulty incorporating their national and ethnic cultures into a cohesive sense of self. These bicultural individuals were also particularly sensitive to specific tensions between their national and ethnic cultural orientations and saw this incompatibility as a source of internal conflict. If ethnic minorities are continually excluded from the national identity and reminded that they do not typify what it means to be American, it would be expected that they experience some degree of internal conflict.

Research on the perceived interrelations between multiple social identities and social identity complexity theory suggests that the less a person perceives the different groups to which he/she belongs as being similar to each other, the more complex his or her social identity will be (Roccas \& Brewer, 2002). When multiple group identities are not convergent, they may become conflicting or even competing, such that the individual feels he/she must choose between one identity or another. In the case of the perpetual foreigner stereotype, individuals whose American identity is often called into question may conclude that they are not perceived as being as American as European Americans. Thus, we hypothesized that one's awareness of being perceived by others as a foreigner would predict one's sense of conflict between ethnic and national identities.

Sense of Belonging in America-Additionally, we investigated whether awareness of the perpetual foreigner stereotype is associated with feelings of belonging in America. A study of ethnic and American identity among ethnic minority adolescents suggested that many feel as if American or mainstream culture generally means White and thus does not include them (Phinney, Cantu, \& Kurtz, 1997). According to this research, American identity is likely to be associated with a heightened sense of belonging to the White majority for European Americans. Conversely, it can be expected that membership in an ethnic minority group is associated with a relatively lowered sense of belonging to the mainstream culture. Such seems to be the case in research based on social dominance theory (Sidanius, Feshbach, Levin, \& Pratto, 1997), which suggests that belongingness to the nation as a whole is more strongly and positively associated with membership in the dominant ethnic 
group and less strongly associated with membership in subordinate ethnic groups. Simply being a member of an ethnic minority seems to entail a certain degree of exclusion from the national identity, potentially contributing to feelings of marginalization and a decreased sense of belonging to mainstream America.

Further evidence for ethnic minorities' relative lack of sense of belonging in America may be seen in research on national attachment, in which European Americans reported the greatest amount of patriotism and nationalism compared to Asian Americans, Latino/as, and African Americans (Sidanius et al., 1997). Minorities' relative lack of patriotism (defined as a love for one's country and its major symbols) and nationalism (the desire for the dominance of one's own nation over others) may be attributable to the "exclusionary patriotism" that emerges in a multiethnic society (Sidanius \& Petrocik, 2001). According to this perspective, the socially dominant group is more identified with the nation's symbols and public institutions, which may lead to questions like "Where are you really from?" directed at visible minorities in various countries around the world where there is an immigrant or ethnic minority population. In the United States, this unequal association between that which is American and different ethnic groups may contribute to and perpetuate the exclusion of ethnic minorities from the national identity. If one group enjoys a greater sense of identification with the mainstream culture, then other groups who do not fit the majority picture can be expected to feel excluded or marginalized from this identity. Thus, based on the above concurrent findings on sense of belonging and national attachment, we expected individuals who feel frequently reminded of their perpetual foreigner status and consequently psychologically denied the American identity to feel marginalized from mainstream American society and to experience a lessened sense of belonging to the national identity. In other words, we hypothesized that an individual's sense of belonging to mainstream American culture would be predicted by his/her awareness of being perceived as a foreigner.

\section{PERPETUAL FOREIGNER STEREOTYPE AND PSYCHOLOGICAL ADJUSTMENT}

In addition to the relations with identity, we were also interested in the association between awareness of the perpetual foreigner stereotype and psychological adjustment, including mental health (depression) and well-being (hope and life satisfaction). Previous research suggests that subtle forms of racism, such as racial micro-aggressions and the perpetual foreigner stereotype, may be detrimental to victims' psychological health, like oldfashioned, overt racism (Sue, Capodilupo, et al., 2007). For example, targets of racial microaggressions report experiencing anxiety, stress, helplessness, academic disengagement, anger, and frustration (Smith, Allen, \& Danley, 2007; Solórzano, Ceja, \& Yosso, 2000). The perpetual foreigner stereotype is particularly salient for Asian Americans, for whom being treated as an alien in one's own land is associated with feelings of inferiority, discomfort, and isolation (Sue, Bucceri, Lin, Nadal, \& Torino, 2007). Although the above studies provide a rich and detailed understanding of racial microaggressions, including the perpetual foreigner stereotype, they are all purely qualitative in nature and restricted to one ethnic group. In the current set of quantitative studies, we hypothesized that awareness of the perpetual foreigner stereotype will predict higher levels of depression and lower levels of hope and life satisfaction for both Latino/as and Asian Americans (Study 3, which does not include African American participants). These adjustment variables, which include psychological symptoms and positive functioning, have been the focus of much research on perceived discrimination (e.g., Klonoff \& Landrine, 1999; Neto, 2001; discussed below), so they were chosen to provide evidence of incremental validity for the perpetual foreigner stereotype construct. 


\section{THE ROLE OF PERCEIVED DISCRIMINATION}

When studying identity and psychological adjustment among ethnic minorities, it is important also to consider the role played by perceived discrimination. It could be said that perceived discrimination, as it is typically measured, refers to a more blatant form of discrimination than the perpetual foreigner stereotype, which constitutes a more subtle form of discrimination (Devos \& Banaji, 2005; Sue, Capodilupo, et al., 2007). Experiences with both forms of discrimination may have negative implications for ethnic minorities, and they may independently account for the identity and psychological outcomes of interest. For example, with regard to identity, a study on Chinese Americans found that perceived discrimination predicts a greater sense of conflict between one's ethnic and national identities (Benet-Martínez \& Haritatos, 2005). Furthermore, perceived discrimination is related to a lower sense of belonging among Latino/a college students (Levin, Van Laar, \& Foote, 2006). Previous research has also found consistent and moderate associations between perceived discrimination and psychological maladjustment. For example, perceived discrimination predicts distress symptoms, such as depression and anxiety, for African American adults (Klonoff \& Landrine, 1999; Klonoff, Landrine, \& Ullman, 1999; Pieterse $\&$ Carter, 2007). Perceived discrimination is also related to higher depression, anxiety, and psychosomatic symptoms for Vietnamese adolescents in Finland (Liebkind, JasinskajaLahti, \& Solheim, 2004) and Latino/a adolescents in the United States (Smokowski \& Bacallao, 2007). In addition, perceived discrimination has been theorized to be related to lowered hope (Adams et al., 2003), and it has been found to be related to lowered life satisfaction for immigrants in several different settlement countries (e.g., Neto, 2001; Sam, 2001; Vohra \& Adair, 2000). Based on these findings, we expected that perceived discrimination would be related to identity and psychological adjustment, but we hypothesized that the perpetual foreigner stereotype would predict identity and psychological adjustment above and beyond perceived discrimination.

\section{THE CURRENT STUDIES}

The goals of the current studies were two-fold: (1) to examine the perpetual foreigner stereotype and perceived discrimination in different ethnic minority groups, and (2) to determine the potential implications of the perpetual foreigner stereotype for individuals' identity and psychological adjustment. Specifically, we hypothesized that exposure to the perpetual foreigner stereotype and discrimination would be a more common experience for ethnic minorities than for European Americans, such that Asian Americans, Latino/as, and African Americans would report both higher awareness of the perpetual foreigner stereotype and higher perceived discrimination as compared to European Americans. Moreover, after controlling for the effects of perceived discrimination, the perpetual foreigner stereotype should predict (a) a greater sense of conflict between one's ethnic and national identities, (b) a lower sense of belonging to mainstream American society, (c) higher levels of depression symptoms, (d) lower levels of hope, and (e) lower levels of life satisfaction among ethnic minorities. We tested the first hypothesis about awareness of the perpetual foreigner stereotype using data from Asian Americans (Studies 1 and 3), Latino/as (Studies 1 and 3), and African Americans (Study 2); hypotheses about the potential implications of the stereotype on identity using data from all three ethnic minority groups (Studies 1 and 2); and hypotheses about the potential implications of the stereotype on psychological adjustment using data from Asian Americans and Latino/as (Study 3).

\section{STUDY 1}

To examine awareness of the perpetual foreigner stereotype and perceived experiences of discrimination among different ethnic groups, we collected data from Asian Americans, 
Latino/as, and European Americans in Study 1. We also examined the link between the awareness of being viewed as a perpetual foreigner and important facets of identity.

\section{METHOD}

Participants-Participants were 836 undergraduate students from a large, public university on the West Coast of the United States. There were 231 Asian Americans, 211 Latino/as, and 394 European Americans. The sample ranged in age from 17 to 42 years $(M=$ $19.15, S D=2.01)$, most of whom were college freshmen, and there were $568(68.0 \%)$ women. All participants were American citizens, and most European Americans were third+ generation Americans, whereas most Asian Americans and Latino/as were second+ generation Americans. See Table 1 for complete participant demographics.

Measures-Participants completed a series of measures assessing perceived discrimination, awareness of the perpetual foreigner stereotype, perception of conflict between ethnic and national identities, sense of belonging to American culture, and basic demographics. All items were rated on a 5-point Likert-type scale $(1=$ strongly disagree to $5=$ strongly agree). Table 2 shows arithmetic means, standard deviations, and Cronbach's alphas for all scales, and Table 3 shows correlations among measured variables.

Perceived Discrimination: To measure perceived discrimination, we used the Perceived Discrimination subscale (9 items) from the Scale of Ethnic Experience (Malcarne, Chavira, Fernandez, \& Liu, 2006). Sample items include: "In my life, I have experienced prejudice because of my ethnicity" and "Discrimination against my ethnic group is not a problem in America" (reverse scored).

Awareness of the Perpetual Foreigner Stereotype: Thirteen items measured the extent to which participants believed they were perceived as a foreigner (as opposed to an American citizen) by others, without reference to the race or ethnicity of the perpetrator. Sample items include: "Sometimes people think I am a foreigner" and "Most people have difficulty viewing me as an American." These items were developed specifically for the present research and were generated using input from an ethnically diverse group of college students (see Appendix).

Perception of Identity Conflict: Six items measured the extent to which participants experienced a conflict between their ethnic and national identities. Some of these items were modified from the conflict subscale of the Bicultural Identity Integration Scale-Version 1 (Benet-Martínez \& Haritatos, 2005) to focus on national and ethnic identities (rather than on cultural identities) for this study. Sample items include: "I am conflicted between my ethnic and American identities" and "In some situations, I feel pressured to choose between my American and ethnic identities."

Sense of Belonging: To measure participants' feelings of belonging to mainstream American society, we used the Mainstream Comfort subscale (6 items) from the Scale of Ethnic Experience (Malcarne et al., 2006). Sample items include: "I feel like I belong to mainstream American culture" and "I think of myself as a typical American."

\section{PROCEDURE}

Participants were recruited through advertisements in the daily campus newspaper (paid) and the psychology department subject pool (unpaid). Paid respondents were given $\$ 15$, and subject pool respondents received partial credit for an introductory psychology course for their participation in the study. All participants completed all questionnaires on a computer in small groups of up to 4 . Computers were located in cubicles in a small lab setting, and 
there were screens between each computer desk for privacy. Measures were completed in the following order: awareness of the perpetual foreigner stereotype, perception of conflict between ethnic and national identities, Scale of Ethnic Experience (including the perceived discrimination and sense of belonging subscales), and demographics.

\section{RESULTS}

As expected, contrast analyses showed that European Americans $(M=1.96, S D=0.59)$ reported significantly lower perceived discrimination than Asian Americans $(M=3.00, S D=$ $0.65)$ and Latino/as $(M=3.51, S D=0.64)$ in our sample; $\lambda=-2,1,1 ; t(833)=30.19, p=$ $7.23 \times 10^{-136}, r_{\text {contrast }}=.72,95 \% \mathrm{CI}: .70$ to .76 . Contrast analyses also showed that European Americans $(M=1.57, S D=0.49)$ reported significantly lower awareness of the perpetual foreigner stereotype toward the self than Asian Americans $(M=2.71, S D=0.67)$ and Latino/as $(M=2.65, S D=0.75) ; \lambda=-2,1,1 ; t(760.53)=26.42, p=1.13 \times 10^{-109}$, $r_{\text {contrast }}=.68,95 \%$ CI: .64 to .72 . In sum, as compared to European Americans, ethnic minorities perceived more discrimination toward them and their ethnic group, and they were more aware that others perceive them as less American and more foreign. These findings are in line with previous research suggesting that ethnic minorities are indeed more aware that they are stereotyped as foreigners (Barlow et al., 2000; Cheryan \& Monin, 2005; Liang et al., 2004).

Not only did European Americans report significantly lower perceived discrimination and awareness of the perpetual foreigner stereotype than Asian Americans and Latino/as in our sample (see Table 2), their arithmetic means were well below the midpoint of the scales. This suggests that perceived discrimination and the perpetual foreigner stereotype are not routinely experienced by members of this ethnic group. Because the goal of our study was to examine the relation between these two forms of ethnic discrimination and identity, we did not include European American participants in the following regression analyses.

To test our hypothesis that awareness of the perpetual foreigner stereotype predicts the outcomes of interest above and beyond perceived discrimination, we conducted hierarchical regression analyses separately for Asian Americans and Latino/as (see Table 4 for regression results). Using data from Asian Americans only, we found that even after controlling for perceived discrimination, awareness of the perpetual foreigner stereotype was a significant predictor of both perception of identity conflict, $\Delta R^{2}=.14, F(1,228)=44.12, p$ $=2.24 \times 10^{-10}$, and lower sense of belonging to American culture, $\Delta R^{2}=.14, F(1,228)=$ $44.38, p=2.00 \times 10^{-10}$. Likewise, using data from Latino/as only, we found that awareness of the perpetual foreigner stereotype significantly predicted perception of identity conflict, $\Delta R^{2}=.18, F(1,208)=55.58, p=2.38 \times 10^{-12}$, and lower sense of belonging to American culture, $\Delta R^{2}=.24, F(1,208)=78.50, p=3.60 \times 10^{-16}$, over and above perceived discrimination.

\section{STUDY 2}

Based on research on "exclusionary patriotism" (Sidanius \& Petrocik, 2001), we would expect African Americans also to feel excluded from the national identity and marginalized from mainstream American society, relative to their European American counterparts. This sense of exclusion and marginalization may come in subtle forms, such as implying that African Americans are not typical Americans (even if most of them are not seen as foreigners in the common meaning of the term). Thus, to determine whether findings on Asian Americans and Latino/as in Study 1 extend to African Americans, we conducted Study 2. 
Participants-Participants were 151 undergraduate students from the same large, public university on the West Coast of the United States. There were 89 African Americans and 62 European Americans. The sample ranged in age from 18 to 45 years $(M=19.62, S D=4.04)$, most of whom were college freshmen, and there were 111 (73.5\%) women. All participants were American citizens, and most participants were third+ generation Americans. See Table 1 for complete participant demographics.

Measures-Participants in Study 2 were administered the same measures as in Study 1: perceived discrimination, awareness of the perpetual foreigner stereotype, perception of conflict between ethnic and national identities, sense of belonging to American culture, and basic demographics. All items were rated on a 5-point Likert-type scale, ranging from $1=$ strongly disagree to $5=$ strongly agree. Table 2 shows arithmetic means, standard deviations, and Cronbach's alphas for all scales, and Table 5 shows correlations among measured variables.

Procedure-Study 2 participants were recruited through the same methods as Study 1 participants, and they completed the study in the same setting as Study 1 participants. Measures were completed in the same order as in Study 1.

\section{RESULTS}

As expected, European Americans $(M=2.11, S D=0.58)$ reported significantly lower perceived discrimination than African Americans $(M=3.92, S D=0.59)$ in our sample, $t(149)=18.68, p=7.25 \times 10^{-41}, r=.84,95 \% \mathrm{CI}$ : .78 to .88 (see Table 2). In addition, European Americans $(M=1.54, S D=0.55)$ reported significantly lower awareness of the perpetual foreigner stereotype toward the self than African Americans $(M=2.33, S D=$ $0.64) ; t(149)=7.83, p=8.33 \times 10^{-13}, r=.54,95 \%$ CI: .42 to .65 . As in Study 1, we conducted hierarchical regression analyses to determine whether awareness of the perpetual foreigner stereotype among African Americans predicts the outcomes of interest above and beyond perceived discrimination (see Table 4 for regression results). We found that awareness of the perpetual foreigner stereotype was a significant predictor of perception of identity conflict, $\Delta R^{2}=.07, F(1,86)=8.12, p=.005$, and lower sense of belonging to American culture, $\Delta R^{2}=.26, F(1,86)=32.18, p=1.85 \times 10^{-7}$, over and above perceived discrimination.

Thus, results from Studies 1 and 2 suggest that for the three major American ethnic minority groups in our samples-Asian Americans, Latino/as, and African Americans-the perpetual foreigner stereotype is an important predictor of identity, such that participants who report that they are seen as perpetual foreigners also are more likely to perceive conflict between their national and ethnic identities and feel less comfortable in mainstream American culture, even when we control for perceived discrimination. In addition, although there is a reliable small-medium correlation between these two variables (awareness of the perpetual foreigner stereotype and perceived discrimination; see Tables 3 and 5) in these three samples, they each independently account for the identity outcomes of interest.

\section{STUDY 3}

In addition to examining identity, we also wanted to determine whether the perpetual foreigner stereotype is an important predictor of psychological adjustment; thus, we conducted Study 3. Specifically, we were interested in whether awareness of the perpetual foreigner stereotype predicts mental health (depression) and well-being (hope and life 
satisfaction) above and beyond perceived discrimination among Latino/as and Asian Americans.

\section{METHOD}

Participants-Participants were 165 Latino/a and 56 Asian American undergraduate students from the same large, public university on the West Coast of the United States. Because of the relative difficulty of recruiting African American participants on the campus, we did not include this ethnic group in Study 3. The Latino/a sample ranged in age from 18 to 32 years $(M=19.47, S D=2.16)$, and the Asian American sample ranged in age from 18 to 24 years $(M=19.64, S D=1.38)$. Most of both samples were college freshmen or sophomores. There were 104 (63.0\%) Latinas and 37 (66.1\%) Asian American women. All participants were American citizens, and most of them were second+ generation Americans. See Table 1 for complete participant demographics.

Measures-In addition to completing the measures from Study 1 (perceived discrimination, awareness of the perpetual foreigner stereotype, perception of conflict between ethnic and national identities, sense of belonging to American culture, and basic demographics), participants in Study 3 completed measures of psychological adjustment: mental health (depression) and well-being (hope and life satisfaction). Table 2 shows arithmetic means, standard deviations, and Cronbach's alphas for all scales, and Table 6 shows correlations among measured variables for both samples.

Depression: We used the Center for Epidemiologic Studies Depression Scale (20 items; Radloff, 1977) to assess depression symptoms, including depressive feelings and behaviors. Respondents were asked to rate their level of depressive symptomatology during the previous 7 days, including the day of the study, on a 4-point Likert-type scale, $1=$ rarely or none of the time $(<1$ day) to $4=$ most or all of the time $(5-7$ days). Sample items include: "I was bothered by things that usually don't bother me" and "I felt sad."

Hope: Six items of the State Hope Scale measured the extent to which participants felt hopeful (sense of agency or "belief in one's capacity to initiate and sustain actions" and pathways to reach goals or "belief in one's capacity to generate routes") about their lives currently (Snyder et al., 1996, p. 321). Respondents were asked to rate the items on an 8point Likert-type scale $(1=$ definitely false to $8=$ definitely true $)$. Sample items include: "At the present time, I am energetically pursuing my goals" (agency) and "There are lots of ways around any problem that I am facing now" (pathways).

Life Satisfaction: Five items from the Satisfaction With Life Scale measured the extent to which participants feel satisfied with their lives currently (Diener, Emmons, Larsen, \& Griffin, 1985). Respondents were asked to rate the items on a 7-point Likert-type scale (1= strongly disagree to $7=$ strongly agree). Sample items include: "In most ways my life is close to my ideal" and "I am satisfied with my life."

Procedure-Study 3 participants were recruited through the same methods as Study 1 participants, and they completed the study in the same setting as Study 1 participants. The psychological adjustment measures were randomized in this study, and they were administered after the discrimination and identity measures, before the basic demographics.

\section{RESULTS}

Replicating our Study 1 results with Latino/as and Asian Americans, we found that even after controlling for perceived discrimination, awareness of the perpetual foreigner 
stereotype was a significant predictor of perception of identity conflict and lower sense of belonging for both groups in Study 3 (see Table 4 for regression results).

Furthermore, we found that for Latino/as, awareness of the perpetual foreigner stereotype was a marginal predictor of depression over and above perceived discrimination, $\Delta R^{2}=.02$, $F(1,162)=3.53, p=.06$. Contrary to our hypothesis, awareness of the perpetual foreigner stereotype did not significantly predict hope, $\Delta R^{2}=.003, F(1,162)=0.45, p=.50$, or life satisfaction, $\Delta R^{2}=.008, F(1,162)=1.40, p=.24$, above and beyond perceived discrimination for Latino/as.

For Asian Americans, awareness of the perpetual foreigner stereotype was not a significant predictor of depression over and above perceived discrimination, $\Delta R^{2}=.02, F(1,53)=1.09$, $p=.30$. However, it significantly predicted hope, $\Delta R^{2}=.09, F(1,53)=5.31, p=.03$, and life satisfaction, $\Delta R^{2}=.07, F(1,53)=5.47, p=.03$, above and beyond perceived discrimination for Asian Americans.

In summary, results from Study 3 suggest that for Asian Americans and Latino/as, the perpetual foreigner stereotype is a predictor of different types of psychological adjustment. In particular, participants who report that they are seen as perpetual foreigners report more depressive symptoms (for Latino/as), and lower hope and lower life satisfaction (for Asian Americans), even when we control for perceived discrimination.

\section{DISCUSSION}

The present research sought to systematically document ethnic minorities' awareness of being stereotyped as perpetual foreigners and examine the links between this awareness, identity, and psychological adjustment. Together, our studies demonstrate that to various degrees, ethnic minorities but not European Americans perceive that they are the targets of the perpetual foreigner stereotype, and that this subtle form of exclusion is linked to ethnic minorities' identity and some types of psychological adjustment. Specifically, as predicted, Asian Americans (Study 1), Latino/as (Study 1), and African Americans (Study 2) report significantly higher awareness of the perpetual foreigner stereotype toward them than do European Americans (Studies 1 and 2). ${ }^{1}$ Also as hypothesized, variations in the awareness of being stereotyped as a foreigner is associated with perceptions of conflict between an individual's ethnic and national identities, even after controlling for perceived discrimination, providing evidence of incremental validity for the perpetual foreigner construct (Studies 1-3). Asian Americans, Latino/as, and African Americans who perceive that they are not seen as Americans by others report experiencing greater tension between their ethnic and national identities than those who are less cognizant of these perceptions. As was shown in research on bicultural identity integration (Benet-Martínez \& Haritatos, 2005), it may be more difficult for some members of an ethnic minority group to incorporate their national and ethnic cultures into a cohesive sense of self. These results may have implications for social identity complexity theory (Roccas \& Brewer, 2002), which suggests that the less a person perceives the different groups to which he/she belongs as being similar to each other, the more complex his/her social identity will be. The current findings suggest

\footnotetext{
${ }^{1}$ In absolute terms, Latino/as (Studies 1 and 3) and African Americans reported relatively high rates of perceived discrimination, with group means well above the midpoint of the rating scale, suggesting that on average, they tend to perceive discrimination toward themselves and their group. However, none of the group means on the perpetual foreigner scale were above the midpoint. Thus, in absolute terms, none of the groups in Studies 1-3 reported being treated as perpetual foreigners to a great extent. Participants also reported low identity conflict (group means below the midpoint across the 3 studies) and high sense of belonging (group means above the midpoint across the 3 studies). In terms of adjustment, Latino/a, and Asian American participants in Study 3 were relatively hopeful and satisfied with their lives (group means above the midpoint) and reported relatively few depression symptoms (group means below the midpoint).
} 
that some ethnic minorities' awareness of being perceived as foreigners may contribute to the perception that their ethnic and national identities are dissimilar and even incompatible, thereby forcing them to maintain a more complex social identity. This could be a source of conflict for these individuals, who may have to choose between their ethnic and national identities (Benet-Martínez \& Haritatos, 2005). Compared with European Americans, whose American identity is readily recognized, members of ethnic minority groups, who are cognizant that their American identity is viewed skeptically by others, experience significantly more tensions in their efforts to form a unified and integrated identity.

The awareness of being perceived as a foreigner also is associated with weakened sense of belonging in America (Studies 1-3). As hypothesized, the extent to which an individual is aware of being viewed as a foreigner is highly correlated with his/her inability to feel part of the national identity, even after controlling for perceived discrimination. Some ethnic minorities, aware of the stereotypes against them, may be led to question whether or not they truly belong in the United States. If fellow Americans treat them as outsiders or as if they do not represent that which is American, how can minority group members be expected to see themselves as American? These findings support the idea that many ethnic minorities see mainstream American culture as generally meaning White and thus feel excluded from the national identity (see also Phinney et al., 1997). Consequently, Asian Americans', Latino/ as', and African Americans' awareness of being perceived as not American may ultimately inhibit their ability to feel like they belong in America or lead to a relative dis-identification with mainstream American culture. These findings may have implications for ethnic minority group participation in civic life, including voting, volunteerism, military service, and other aspects of citizen involvement, all of which are bolstered by a sense of identification with the group (in this case, the American identity). Perceiving exclusion in the form of the perpetual foreigner stereotype may discourage some ethnic minorities from actively participating in American society.

In addition to the strong correlations between ethnic minorities' awareness of being stereotyped and their identity, their subjective experiences with the perpetual foreigner stereotype are moderately linked to adjustment. As expected, ethnic minorities who are more aware of the perpetual foreigner stereotype tend to report greater depression (for Latino/as, Study 3) and lower hope or life-satisfaction (for Asian Americans, Study 3), even after controlling for perceived discrimination, providing further evidence for the incremental validity of the perpetual foreigner construct. ${ }^{2}$ It should be emphasized that the patterns of associations between the perpetual foreigner stereotype and adjustment are different for Latino/as and Asian Americans. It is possible that the perpetual foreigner stereotype operates differently for these two groups. For example, American history-with wars in Japan, Korea, and Viet Nam, and fears of the yellow peril with regard to Chinese immigrants-is rife with conceptions of Asians (and thus Asian Americans) as foreign and dangerous enemies (Takaki, 1998). Conversely, the messages regarding the foreign-ness of Latino/as are mixed. Although some Latino/as are racially White, and some have ancestors who lived on this land before the United States was founded, the recent immigration debates have focused on Latino/as, often labeling them as illegal aliens. It is also possible that adjustment and well-being are expressed and reported differently by Latino/as and Asian Americans. For example, some Asian Americans may find that it is more culturally acceptable to

\footnotetext{
${ }^{2}$ In previous research, perceived discrimination predicted depression symptoms for Latino/as (e.g., Romero \& Roberts, 2003; Smokowski \& Bacallao, 2007); however, it was not a significant predictor of depression symptoms in Study 3 reported here. There may be important differences between our sample and the samples of Latino/as studied in previous research that may account for the difference in findings. For example, researchers have found that English language competence is another important predictor of fewer depression symptoms for Latino/a youth (e.g., Rumbaut, 1995). Because our sample consists of college students, they may be more competent in English than the adolescents typically studied in previous research, and this language competency may buffer the negative impact of perceived discrimination on depression symptoms for our sample.
} 
experience depression psychosomatically and to report physical problems than it is to report symptoms of depression (Chun, Enomoto, \& Sue, 1996; U.S. Department of Health and Human Services, 2001).

Overall, our findings are in line with the racial microaggressions perspective, which suggests that subtle forms of racism, such as being perceived by others as foreigners even when one identifies as American, may be detrimental to the victim's psychological adjustment (Sue, Capodilupo, et al., 2007). American ethnic minorities who feel that they are frequently perceived as foreigners and denied their ingroup status may feel conflicted about their national identity and have a sense of cultural homelessness, which in turn can lead to poorer overall psychological adjustment. That is, these feelings of conflict and exclusion may cause ethnic minorities to experience depression symptoms, lose hope, and become less satisfied overall with their lives. These findings may also be interpreted in the reverse direction: individuals who have lower overall well-being (experience more identity conflict and lower sense of belonging, more depressive symptoms, feel more hopeless about life, and have lower life satisfaction) also perceive less acceptance from mainstream American society, or have a generally more negative outlook on life. Thus, they also report more awareness of the perpetual foreigner stereotype. More research is needed to determine the complex causal pathways among these variables.

Another way in which exposure to the perpetual foreigner stereotype may negatively impact ethnic minorities' psychological adjustment can be viewed in light of research on stigma consciousness (Pinel, 1999). According to this theoretical framework, individuals or groups that regularly contend with stereotypical or prejudicial reactions have higher expectations of being the target of these types of responses than groups that do not. Similarly, ethnic minorities who are frequently reminded of their perpetual foreigner status may come to expect to be stereotyped in this manner. Our findings highlight the potentially deleterious effects of such expectations, even when the stereotypical or prejudicial reactions are relatively subtle and ambiguous in nature.

\section{LIMITATIONS AND FUTURE DIRECTIONS}

Despite the ethnic diversity of the samples in these studies, all studies used data from undergraduate university students, who represent only a small sub-set of the American population. However, it can be argued that if effects of the perpetual foreigner stereotype can be seen among a well-educated, successful population of individuals, the phenomenon may be even more magnified in other sub-sets of the American population. These other subsets should be sampled in order to determine their level of awareness of being denied the American identity, and whether such awareness is predictive of identity conflict, a lowered sense of belonging to mainstream America, and poor psychological adjustment, as it is for Asian American, Latino/a, and African American undergraduate students.

A second limitation of the current research is its correlational nature. Despite establishing the predictive validity (in the regression sense) of the perpetual foreigner stereotype, it is impossible based on the present set of findings to make claims as to whether one's awareness of being seen as a foreigner is the cause of internal conflict, a lowered sense of belonging to mainstream America, and poor psychological adjustment. Future experimental or longitudinal research is needed to establish this causal relationship. In addition, future studies should examine moderators, such as ethnic identity, social support, and ethnic and mainstream American social networks, that may serve as buffers in the negative link between individuals' awareness of the perpetual foreigner stereotype and their psychological well-being. 


\section{CONCLUSION}

Equality is a core American value, yet when ethnic minorities perceive that their national identity is being denied via marginalizing comments (e.g., You speak English so well), they are being told that they are not as American as European Americans, whose "Americanness" is not called into question. Thus, comments and behaviors that subtly alienate ethnic minorities may perpetuate the commonly held belief (implicit and explicit) that Americanness is Whiteness (Devos \& Banaji, 2005; Phinney et al., 1997). Although the intentions of the perpetrator are unknown, our studies show the importance of the target's perception of such exclusionary experiences. We have demonstrated that these repeated experiences of marginalization, although subtle, are linked to important psychological outcomes for the targets. Specifically, the most important contribution of the present studies is the identification of the potential impact of the awareness of the perpetual foreigner stereotype on one's identity and psychological adjustment. Our results suggest that the simple awareness of being seen as less American may influence an individual's adjustment and the way he/she perceives him/herself. In addition to establishing a foundation upon which to further examine the potentially negative consequences of the perpetual foreigner stereotype for ethnic minorities, the present research provides insight into how an underlying exclusionary national mindset may have nontrivial implications for minority groups' identity and well-being.

\section{Acknowledgments}

This research was supported in part by National Institute of Mental Health Grants R24 MH 065515 and 3R24 MH 065515-06S1.

\section{References}

Adams, V.; Rand, K.; Kahle, K.; Snyder, C.; Berg, C.; King, E., et al. African Americans' hope and coping with racism stressors. In: Jacoby, R.; Keinan, G., editors. Between stress and hope: From a disease-centered to a health-centered perspective. Westport, CT: Praeger/Greenwood; 2003. p. 235-249.

Asamen JK, Berry GL. Self-concept, alienation, and perceived prejudice: Implications for counseling Asian Americans. Journal of Multicultural Counseling and Development. 1987; 15:146-160.

Barlow KM, Taylor DM, Lambert WE. Ethnicity in America and feeling “American”. Journal of Psychology. 2000; 134:581-600. [PubMed: 11092413]

Benet-Martínez V, Haritatos J. Bicultural identity integration (BII): Components and psychosocial antecedents. Journal of Personality. 2005; 73:1015-1050. [PubMed: 15958143]

Cheryan S, Monin B. "Where are you really from?": Asian Americans and identity denial. Journal of Personality and Social Psychology. 2005; 89:717-730. [PubMed: 16351364]

Chun, C-A.; Enomoto, K.; Sue, S. Health care issues among Asian Americans: Implications of somatization. In: Kato, PM.; Mann, T., editors. Handbook of diversity issues in health psychology. New York: PlenumPress; 1996. p. 439-467.

Devos T, Banaji MR. American = White? Journal of Personality and Social Psychology. 2005; 88:447-466. [PubMed: 15740439]

Devos T, Gavin K, Quintana FJ. Say "Adios" to the American Dream? The interplay between ethnic and national identity among Latino and Caucasian Americans. Cultural Diversity and Ethnic Minority Psychology. 2010; 16:37-49. [PubMed: 20099963]

Devos T, Heng L. Whites are granted the American identity more swiftly than Asians: Disentangling the role of automatic and controlled processes. Social Psychology. 2009; 40:192-201.

Devos T, Ma DS. Is Kate Winslet more American than Lucy Liu? The impact of construal processes on the implicit ascription of a national identity. British Journal of Social Psychology. 2008; 47:191-215. [PubMed: 17621413] 
Diener E, Emmons RA, Larsen RJ, Griffin S. The satisfaction with life scale. Journal of Personality Assessment. 1985; 49:71-75. [PubMed: 16367493]

Klonoff EA, Landrine H. Cross-validation of the schedule of racist events. Journal of Black Psychology. 1999; 25:231-254.

Klonoff EA, Landrine H, Ullman JB. Racial discrimination and psychiatric symptoms among Blacks. Cultural Diversity and Ethnic Minority Psychology. 1999; 5:329-339.

Levin S, Van Laar C, Foote W. Ethnic segregation and perceived discrimination in college: Mutual influences and effects on social and academic life. Journal of Applied Social Psychology. 2006; 36:1471-1501.

Liang CTH, Li LC, Kim BSK. The Asian American racism-related stress inventory: Development, factor analysis, reliability, and validity. Journal of Counseling Psychology. 2004; 51:103-114.

Liebkind K, Jasinskaja-Lahti I, Solheim E. Cultural identity, perceived discrimination, and parental support as determinants of immigrants' school adjustments: Vietnamese youth in Finland. Journal of Adolescent Research. 2004; 19:635-656.

Malcarne VL, Chavira DA, Fernandez S, Liu PJ. The scale of ethnic experience: Development and psychometric properties. Journal of Personality Assessment. 2006; 86:150-161. [PubMed: 16599789]

Neto F. Satisfaction with life among adolescents from immigrant families in Portugal. Journal of Youth and Adolescence. 2001; 30:53-67.

Phinney JS, Cantu CL, Kurtz DA. Ethnic and American identity as predictors of self-esteem among African American, Latino, and White adolescents. Journal of Youth and Adolescence. 1997; 26:165-185.

Pieterse AL, Carter RT. An examination of the relationship between general life stress, racism-related stress, and psychological health among black men. Journal of Counseling Psychology. 2007; 54:101-109.

Pinel EC. Stigma consciousness: The psychological legacy of social stereotypes. Journal of Personality and Social Psychology. 1999; 76:114-128. [PubMed: 9972557]

Radloff LS. The CES-D scale: A self report depression scale for research in the general population. Applied Psychological Measurement. 1977; 1:385-401.

Roccas S, Brewer M. Social identity complexity. Personality and Social Psychology Review. 2002; 6:88-106.

Romero AJ, Roberts RE. Stress within a bicultural context for adolescents of Mexican descent. Cultural Diversity and Ethnic Minority Psychology. 2003; 9:171-184. [PubMed: 12760328]

Rumbaut, RG. The new Californians: Comparative research findings on the educational progress of immigrant children. In: Rumbaut, RG.; Cornelius, WA., editors. California's immigrant children: Theory, research, and implications for educational policy. San Diego, CA: Center for U.S.Mexican Studies; 1995. p. 17-69.

Rydell RJ, Hamilton DL, Devos T. Now they are American, now they are not: Valence as a determinant of the inclusion of African Americans in the American identity. Social Cognition. 2010; 28:161-179.

Sam DL. Satisfaction with life among international students: An exploratory study. Social Indicators Research. 2001; 53:315-337.

Sidanius J, Feshbach S, Levin S, Pratto F. The interface between ethnic and national attachment: Ethnic pluralism or ethnic dominance? Public Opinion Quarterly. 1997; 61:102-133.

Sidanius, J.; Petrocik, JR. Communal and national identity in a multiethnic state: A comparison of three perspectives. In: Ashmore, RD.; Jussim, L.; Wilder, D., editors. Social identity, intergroup conflict, and conflict resolution. Oxford: Oxford University Press; 2001. p. 101-129.

Smith WA, Allen WR, Danley LL. "Assume the position... You fit the description": Psychosocial experiences and racial battle fatigue among African American male college students. American Behavioral Scientist. 2007; 51:551-578.

Smokowski PR, Bacallao ML. Acculturation, Internalizing mental health symptoms, and self-esteem: Cultural experiences of Latino adolescents in North Carolina. Child Psychiatry and Human Development. 2007; 37:273-292. [PubMed: 17103301] 
Snyder CR, Sympson SC, Ybasco FC, Borders TF, Babyak MA, Higgins RL. Development and validation of the State Hope Scale. Journal of Personality and Social Psychology. 1996; 70:321335. [PubMed: 8636885]

Solórzano D, Ceja M, Yosso T. Critical race theory, racial microaggressions, and campus racial climate: The experiences of African American college students. Journal of Negro Education. 2000; 69:60-73.

Sue DW, Bucceri J, Lin AI, Nadal KL, Torino GC. Racial microaggressions and the Asian American experience. Cultural Diversity and Ethnic Minority Psychology. 2007; 13:72-81. [PubMed: 17227179]

Sue DW, Capodilupo CM, Torino GC, Bucceri JM, Holder AMB, Nadal KL, Esquilin M. Racial microaggressions in everyday life: Implications for clinical practice. American Psychologist. 2007; 62:271-286. [PubMed: 17516773]

Takaki, R. A larger memory: A history of our diversity, with voices. Boston: Little, Brown and Company; 1998.

U.S. Department of Health and Human Services. Mental health: Culture, race, and ethnicity-A supplement to Mental health: A report of the surgeon general. Rockville, MD: U.S. Department of Health and Human Services, Substance Abuse and Mental Health Services Administration, Center for Mental Health Services; 2001. Retrieved January 17, 2011 from http://www.surgeongeneral.gov/library/mentalhealth/cre/sma-01-3613.pdf

Vohra N, Adair J. Life satisfaction of Indian immigrants in Canada. Psychology and Developing Societies. 2000; 12:109-138.

\section{APPENDIX}

\section{Awareness of the Perpetual Foreigner Stereotype Scale}

1. Most people see me as an American.*

2. Most people have difficulty viewing me as an American.

3. I do not fit what people have in mind when they think of a typical American.

4. Due to my ethnicity, people sometimes assume I am not American.

5. Sometimes people think I am a foreigner.

6. Based on my physical appearance, people assume I am American.*

7. Because of how I speak, people sometimes think I am not a U.S. citizen.

8. Sometimes people interpret what I do or say as if I was not American.

9. When people look at me, they see a foreigner.

10. My ethnic heritage sometimes disqualifies me as American.

11. People sometimes ask me where I am from.

12. People sometimes ask me how I speak English so well.

13. I have to work harder than most people to be accepted as American. 


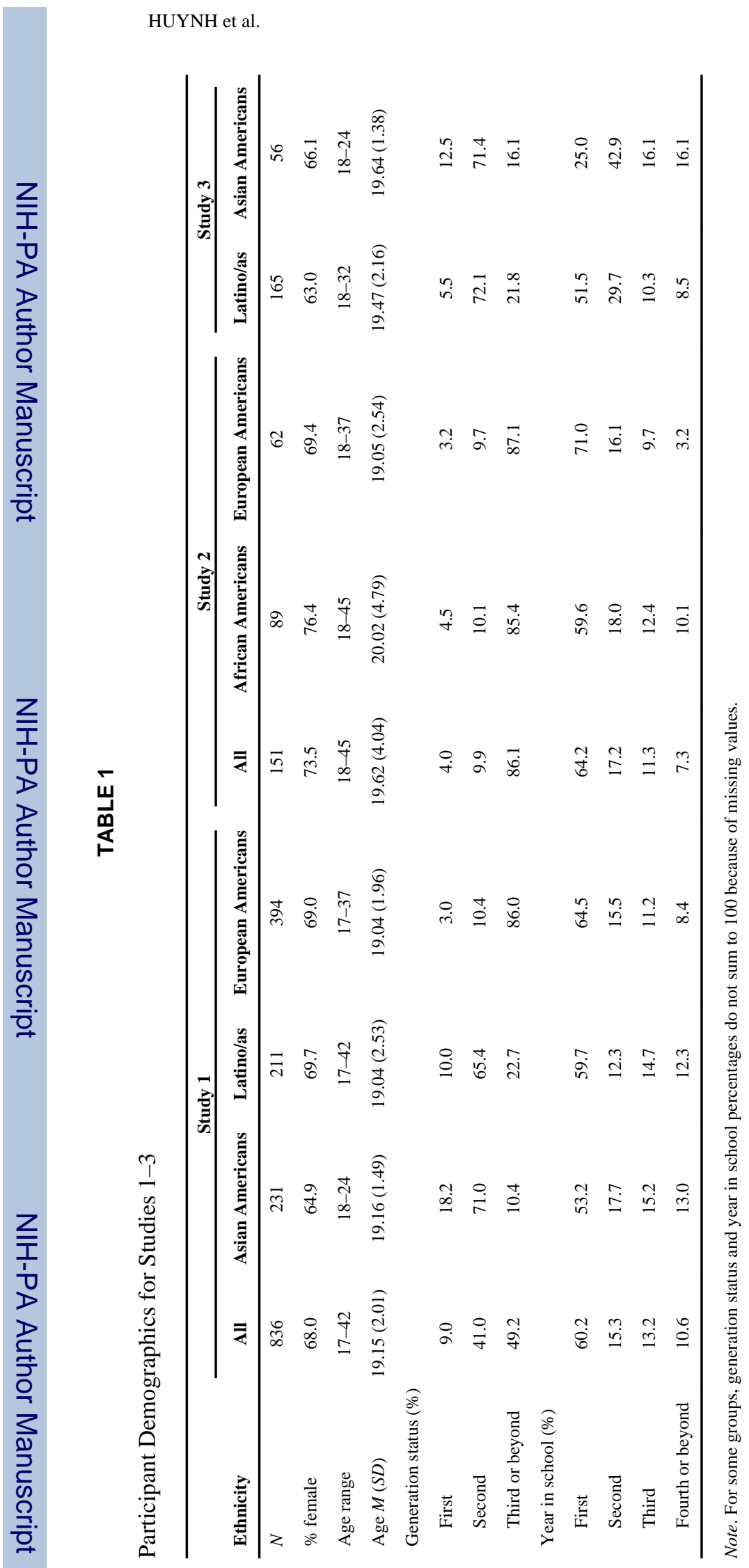

J Soc Clin Psychol. Author manuscript; available in PMC 2011 May 11. 


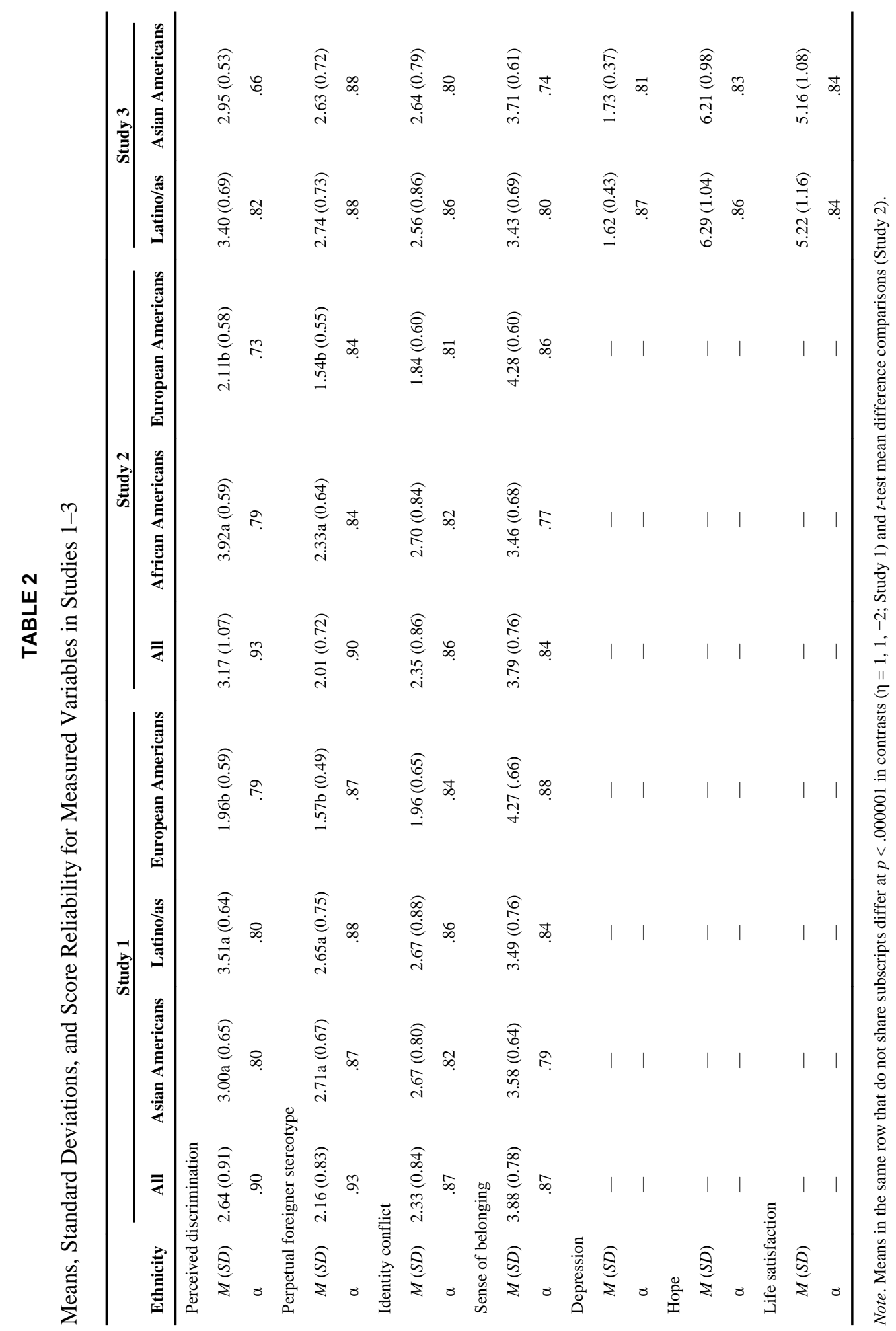


TABLE 3

Correlations Among Measured Variables for Latino/as and Asian Americans in Study 1

\begin{tabular}{lcccc}
\hline & Discrimination & Foreigner & Conflict & Belonging \\
\hline Perceived discrimination & - & .46 & .36 & -.34 \\
Perpetual foreigner stereotype & .40 & - & .50 & -.49 \\
Identity conflict & .41 & .55 & - & -.34 \\
Sense of belonging & -.36 & -.59 & -.39 & - \\
\hline
\end{tabular}

Note. Correlations for Latino/as $(N=211)$ are below the diagonal, and correlations for Asian Americans $(N=231)$ are above the diagonal. All correlations significant at the $p<0.01$ level (two-tailed). 


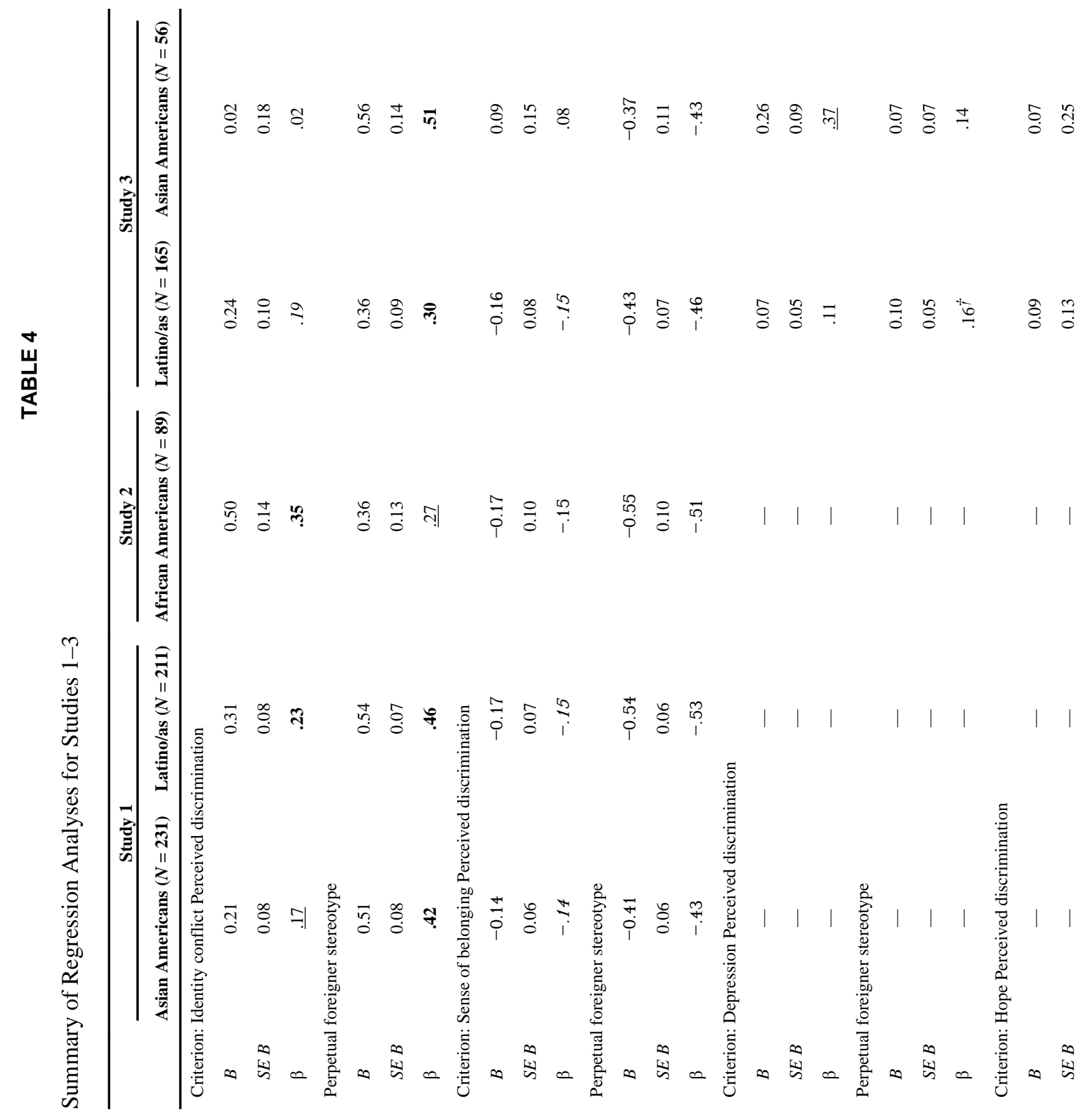




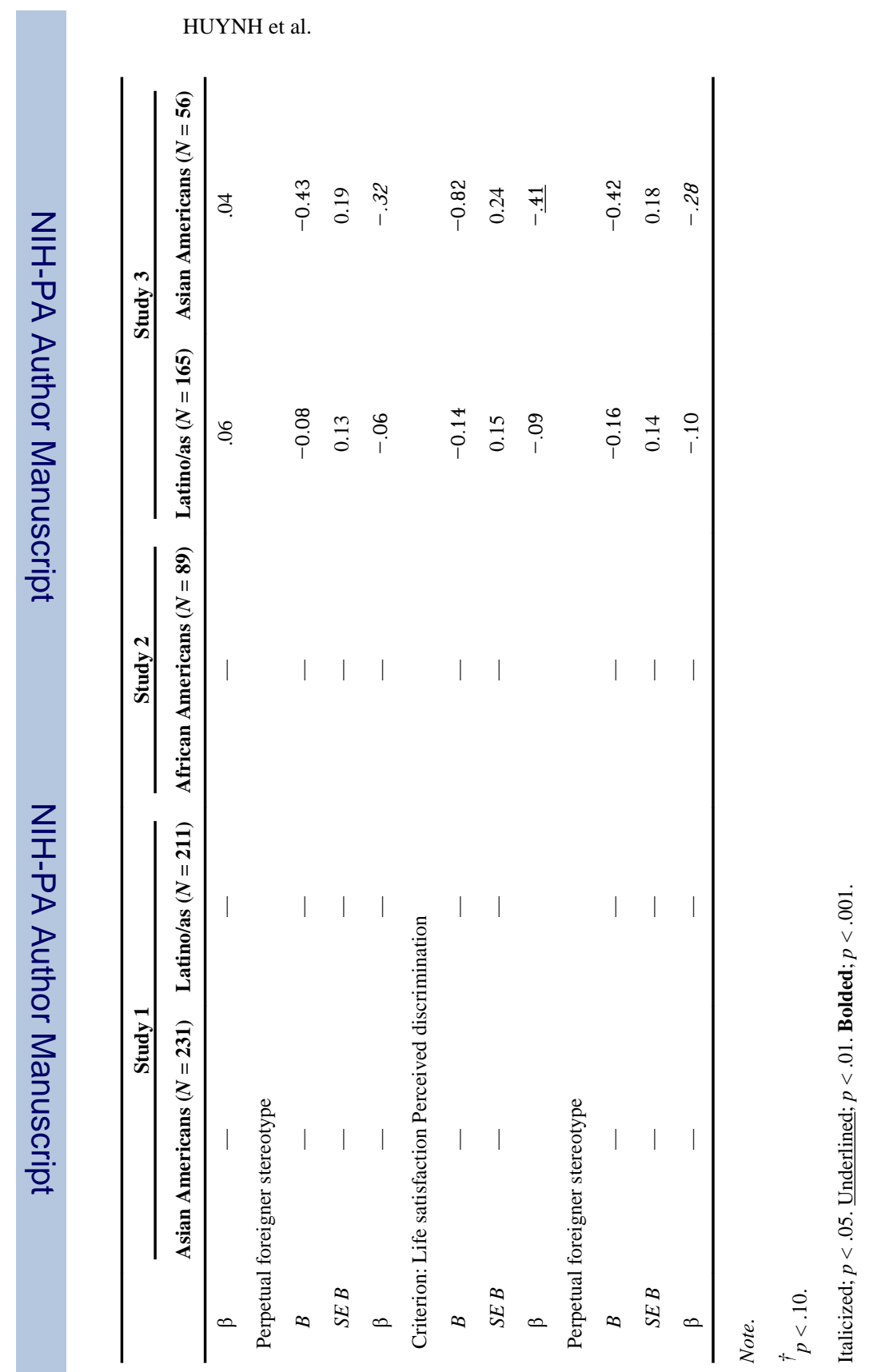

Page 20

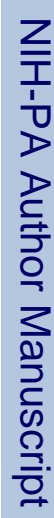

J Soc Clin Psychol. Author manuscript; available in PMC 2011 May 11. 
TABLE 5

Correlations Among Measured Variables for African Americans in Study 2

\begin{tabular}{lcccc}
\hline & Discrimination & Foreigner & Conflict & Belonging \\
Perceived discrimination & - & - & - & - \\
Perpetual foreigner stereotype & .17 & - & - & - \\
Identity conflict &. $\mathbf{4 0}$ &. $\mathbf{3 3}$ & - & - \\
Sense of belonging & -.24 & -.54 & -.19 & - \\
\hline
\end{tabular}

Note. $N=89$. Correlations significant at the 0.05 level (2-tailed) are underlined; correlations significant at the 0.01 level (2-tailed) are bolded. 


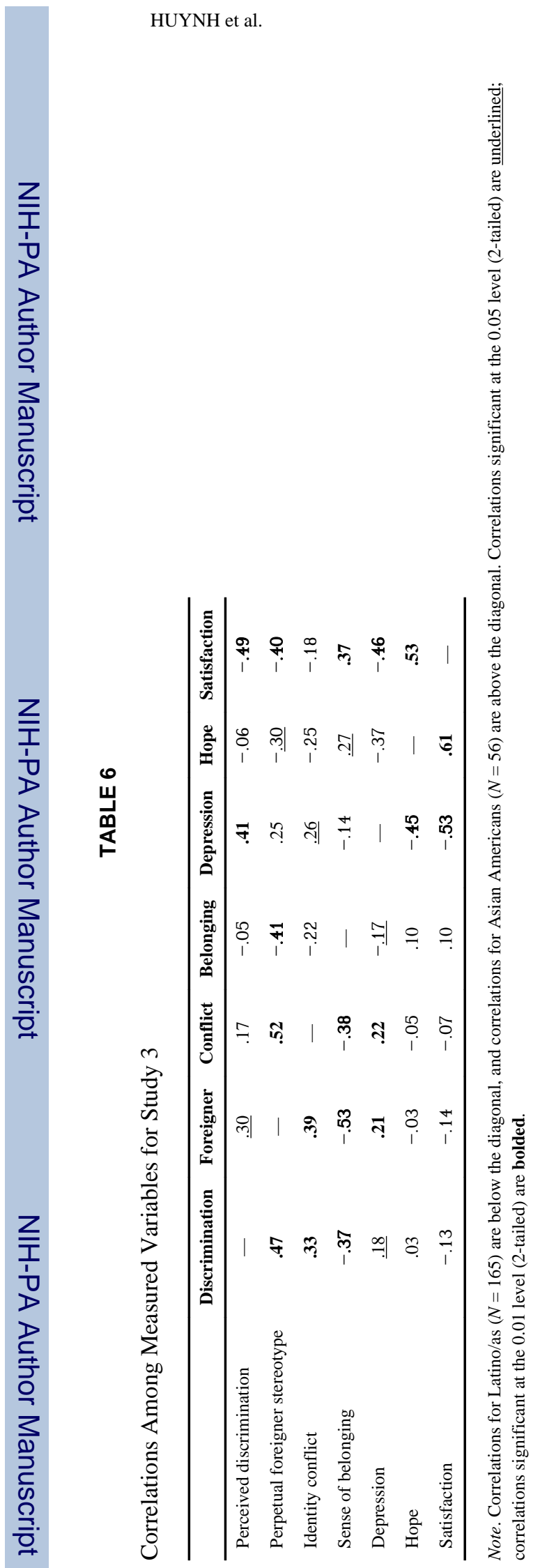

Page 22

J Soc Chin Psychol. Author manuscript; available in PMC 2011 May 11. 